\title{
Can we send patients with large non-resolving pneumothorax home post chest drain removal?
}

\author{
Sanjeet SA Singh", Karim Morcos, Alan JB Kirk \\ From World Society of Cardiothoracic Surgeons 25th Anniversary Congress, Edinburgh \\ Edinburgh, UK. 19-22 September 2015
}

\section{Background/Introduction}

In thoracic surgery, access to the pleural cavity involves a pleurotomy. A chest drain is inserted to allow re-expansion of the lungs post-pleurotomy. This also prevents a tension pneumothorax. Some patients have a residual pneumothorax post chest drain removal noted on chest radiography (CXR) despite having no air leaks. Rates of pneumothorax post chest drain removal vary with figures quoted at 9.3-13.6\%. The majority of these are barely perceptible or small $(<1 \mathrm{~cm}$ from pleural line to the apex of the hemithorax). Some are larger ( $>2 \mathrm{rib}$ spaces in apex or base). For these larger pneumothoraces, is it safe to send patients home?

\section{Aims/Objectives}

To assess the progress of patients discharged with large non-resolving pneumothoraces.

\section{Method}

A retrospective observational study was done at our unit over a 6-month period. All patients had chest drains postoperatively and were discharged if there were no air leaks or worsening of their pneumothorax post drain removal. A repeat CXR was obtained during routine follow up 6 weeks later. Patients with pneumonectomies and permanent thoracostomies were excluded from the study. Air leaks were detected using digital drainage systems.

\section{Results}

There were 158 patients in the study. The mean age was 59.7 years $(\mathrm{SD}=16.6)$. All patients were asymptomatic at the time of discharge and none required further intervention in other hospitals with regards to their pneumothorax. There were $9(5.7 \%)$ patients who were discharged with large residual pneumothorax ( $>2$ rib space) visible on CXR.

Golden Jubilee National Hospital, Clydebank, Dumbartonshire, G81 4DY, UK
The mean age of this cohort was 69.7 years $(\mathrm{SD}=8.8)$. During follow up, these residual spaces were either partially or fully fluid filled with no radiological or symptomatic worsening.

\section{Discussion/Conclusion}

This study found that it was safe to discharge asymptomatic patients with a large pneumothorax provided they are haemodynamically stable and had no air leak.

Published: 16 December 2015

doi:10.1186/1749-8090-10-S1-A190

Cite this article as: Singh et al:: Can we send patients with large nonresolving pneumothorax home post chest drain removal? Journal of Cardiothoracic Surgery 2015 10(Suppl 1):A190.
Submit your next manuscript to BioMed Central and take full advantage of:

- Convenient online submission

- Thorough peer review

- No space constraints or color figure charges

- Immediate publication on acceptance

- Inclusion in PubMed, CAS, Scopus and Google Scholar

- Research which is freely available for redistribution
() Biomed Central 